\title{
Accuracy of the cutoff value of the third molar maturity index: an Egyptian study
}

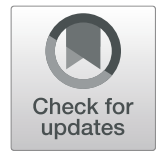

\author{
Amal A. El-Bakary ${ }^{1 *}$ (D) Somaia M. El-Azab ${ }^{1}$, Heba M. Abou El Atta ${ }^{2}$, Luz Andrea Velandia Palacio ${ }^{3}$ and \\ Roberto Cameriere ${ }^{3}$
}

\begin{abstract}
Background: This study aimed to test the sensitivity and specificity of the third molar maturity index $\left(I_{3 M}\right)$ cutoff value to discriminate between individuals above and below 18 years of age in an Egyptian sample.

Material and methods: Digital images of 247 orthopantographs (97 boys and 150 girls) were evaluated. The cutoff value of $I_{3 M}$ obtained from the results of Cameriere et al. (Int J Legal Med 122:493-497, 2008) was evaluated in both girls and boys.

Results: Sensitivity (the proportion of individuals being 18 years of age or older) was $95 \%$ and $73 \%$ in boys and girls, respectively. Meanwhile, specificity (the proportion of individuals younger than 18) was 100\% in boys and $97 \%$ in girls. The proportion of correctly classified boys was $97 \%$ while it was $59 \%$ in girls.

Conclusion: It can be concluded that the third molar maturity index can discriminate between individuals who are 18 years and over and those under 18 with higher accuracy in boys.
\end{abstract}

Keywords: Adolescents, Dental age estimation, Egyptians, Third molar maturity index $\left(l_{3 \mathrm{M}}\right)$

\section{Background}

The age of 18 is the age of legal responsibility. This is important especially with the increased illegal migration. Many illegal African immigrants pass to Europe through Egypt. Illegal immigrants tend to lack reliable documents since they either lose them or even destroy them. The Egypt's state statistics agency (CAPMAS) report said that many children in the age range 10-17 were married and 93.4\% of them were girls, a violation of Egyptian laws which the government aims to combat (ahramonline accessed 11 June 2019). So, providing suitable legal procedures reflecting the transition from childhood to maturity and full criminal responsibility is an important issue in criminal justice (De Luca et al. 2016). That is why forensic age estimation of living individuals is a very important tool to overcome deliberate falsification of age in medicolegal and criminal cases (Cameriere et al. 2015; Gupta et al. 2015).
Teeth development as a mean to evaluate age in children has the advantage of being in a uniform manner from infancy to late adolescence. It is under strong genetic control and shows less environmental influences compared to skeletal maturation (Franklin et al. 2015).

The third molar development assessment is usually applied for those aged 13-23 years (Galic et al. 2015). For estimating the age of 18, Cameriere et al. (2008) published a method that depends on the assessment of the relation between age and the third molar maturity index $\left(\mathrm{I}_{3 \mathrm{M}}\right)$. They found that a cutoff value of 0.08 in Italian population showed $70 \%$ sensitivity and $98 \%$ specificity. It has been tested in many populations and showed high sensitivity and specificity (Deitos et al. 2015; Galic et al. 2015; De Luca et al. 2016). No studies until now have assessed such method on the Egyptian population. So, we aimed to test the sensitivity and specificity of this cutoff value to discriminate between Egyptian individuals above and below 18 years of age.

\footnotetext{
* Correspondence: amal_elbakary@mans.edu.eg; aelbakary2015@gmail.com ${ }^{1}$ Forensic Medicine and Clinical Toxicology Department, Faculty of Medicine, Mansoura University, Mansoura 35516, Egypt

Full list of author information is available at the end of the article
} 


\section{Material and methods Sample}

A sample of 259 orthopantographs (OPGs) from Egyptian subjects aged 13-24 was analyzed. This crosssectional study collected OPGs at random from the digital archive of the Mansoura University, Faculty of Dentistry, during years 2015 and 2017, as well as from private dental clinics, following the ethical standards laid down by the Declaration of Helsinki (2013) and was approved by Mansoura University IRB (code: R.18.11.345). Exclusion criteria were dental pathology affecting the lower left jaw and unknown date of birth.

Following the initial sampling, 12 OPGs were excluded because they did not meet the inclusion criteria, leaving 247 OPGs (97 boys and 150 girls). The digital images were evaluated using an open-source image computeraided drafting program used to process and analyze digital images (Digimizer Image Analysis program).

\section{Assessment of the third molar maturity index $\left(\mathrm{I}_{3 \mathrm{M}}\right)$}

The left lower third molar was examined using the $\mathrm{I}_{3 \mathrm{M}}$ index described in the study by Cameriere et al. (2008) where if the apices of the third molar are completely closed, then $\mathrm{I}_{3 \mathrm{M}}=0$. Otherwise, the distance between the inner sides of the open apex, i.e., apical distance (AD) of mandibular left third molars, was measured and divided by the tooth length $(L)$. If the tooth had two roots (ADa and $\mathrm{ADb}$ ), the sum of these distances was divided by the tooth length $(L)$ (Fig. 1). Measurements were carried out by two different observers.

Twenty randomly selected OPGs were assessed to check for inter-observer reliability and were re-examined after a month interval for intra-observer reliability.

\section{Statistical analysis}

A Microsoft Excel file was used in this study to register the identification number, gender, chronological age, and $I_{3 M}$ value. The cutoff value of 0.08 for $I_{3 M}$ for both genders, obtained from the results of Cameriere et al. (2008), was evaluated. An individual is considered to be 18 years of age or older if $I_{3 M}$ is lower than 0.08 . The sensitivity of the test (i.e., the proportion of subjects $\geq$ 18 years of age who have $\left.\mathrm{I}_{3 \mathrm{M}}<0.08\right)$ together with specificity (i.e., the proportion of individuals younger than 18 who have $I_{3 M}>0.08$ ) was evaluated.

According to Bayes' theorem, post-test probability was written as

$$
\mathrm{PPV}=\frac{\mathrm{Se} p_{0}}{\operatorname{Se} p_{0}+(1-\mathrm{Sp})\left(1-p_{0}\right)}
$$

where positive predictive value (PPV) is the positive predictive value and $p_{0}$ is the prevalence of Egyptian subjects aged between 18 and 24 years of age among all subjects aged between 13 and 24 years old (the studied sample) who live in Egypt based on the demographic data retrieved from Egypt Demographics Profile (2018). The estimated prevalence for girls is $59 \%$ and $60 \%$ for boys.

Intra-class correlation coefficient (ICC) was used to test the intra-observer and inter-observer agreement between the two observers. To evaluate intra-observer and interobserver agreement between both observers, Cohen's kappa was used.

\section{Results}

Age distribution of the sample is shown in Table 1. Individuals $<18$ years were 100 ( 42 boys and 58 girls) while those $\geq 18$ years were 147 ( 55 boys and 92 girls). The mean chronological age of boys and girls were $18.85 \pm$ 3.61 years and $19.11 \pm 4.16$ years, respectively. The minimum age at which complete maturation (union of apices) of the third molar $\left(\mathrm{I}_{3 \mathrm{M}}=0\right)$ was noticed to be 20.07 years for girls and 19.44 years for boys.

The validity of $\mathrm{I}_{3 \mathrm{M}}$ presenting the number of individuals who have $I_{3 M} \geq 0.08$ and $I_{3 M}<0.08$ and those who
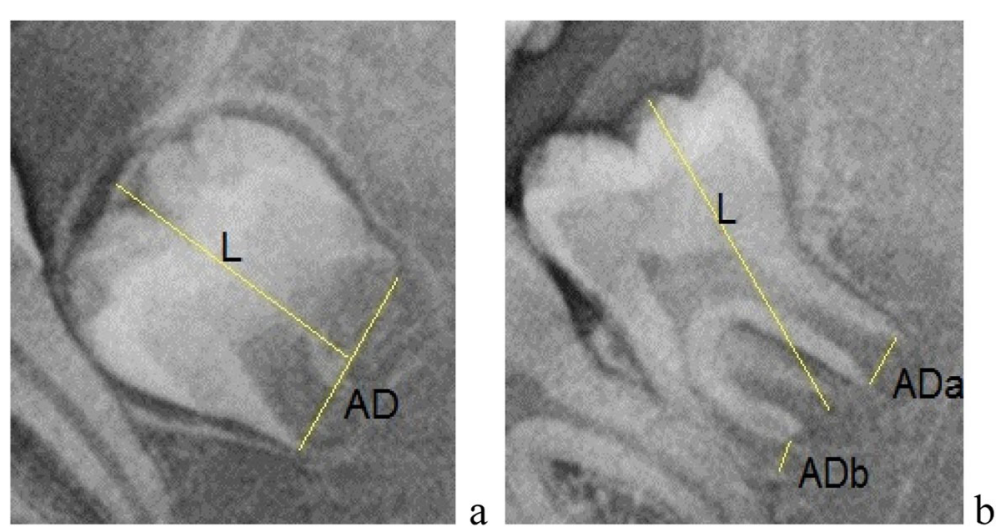

Fig. 1 Measurements of a tooth with one root (a) and two roots (b) where AD apical distance, $L$ length 
Table 1 Sample of panoramic radiographs from Egyptian individuals according to sex and age categories

\begin{tabular}{llll}
\hline Age & $M$ & $F$ & Total \\
\hline 13 & 12 & 14 & 26 \\
14 & 8 & 14 & 22 \\
15 & 10 & 11 & 21 \\
16 & 7 & 9 & 16 \\
17 & 5 & 10 & 15 \\
18 & 6 & 13 & 19 \\
19 & 5 & 23 & 28 \\
20 & 9 & 19 & 28 \\
21 & 14 & 14 & 28 \\
22 & 9 & 12 & 21 \\
23 & 9 & 7 & 16 \\
24 & 3 & 4 & 7 \\
Total & 97 & 150 & 247 \\
\hline
\end{tabular}

$M$ male, $F$ females

are younger than 18 and those not younger than 18 is shown in Tables 2 and 3.

The close association between adult age and positivity of the test (i.e., $\mathrm{I}_{3 \mathrm{M}}<0.08$ ) in girls is shown in Table 2. It was found that 123 out of 150 (82\% (95\% CI 76-88)) were correctly classified. The sensitivity of the test was $73 \%$ (95\% CI 64-82) and its specificity was 97\% (95\% CI 92-100). The PPV was 59\%.

Table 3 displays the close association between adult age and the positivity of the test in the boys. From 97 individuals, 94 were accurately classified (97\% (95\% CI 93-100)). The sensitivity of the test was 95\% (95\% CI $89-100)$ and the specificity was $100 \%$. The PPV was $60 \%$.

The ICC for intra-rater and inter-rater agreement of $\mathrm{I}_{3 \mathrm{M}}$ was $98.7 \%$ (95\% CI 98.4-99.2) and $97.8 \%$ (95\% CI 96-98.2), respectively. Cohen's kappa for intra-rater and inter-rater agreement was 0.93 and 0.86 .

\section{Discussion}

It is important to discriminate minors from adult especially in the absence of documents to avoid criminal violations (Deitos et al. 2015). From this point of view, methods used for age estimation applied in forensic

Table 2 Contingency table of the cutoff value's performance for girls $(n, 150)$

\begin{tabular}{llll}
\hline Test & Age & Total \\
\cline { 2 - 4 } & $<18$ & $\geq 18$ & \\
\hline$\left.\right|_{3 M}<0.08$ & 2 & 67 & 69 \\
$\left.\right|_{3 M} \geq 0.08$ & 56 & 25 & 81 \\
Total & 58 & 92 & 150 \\
\hline
\end{tabular}

$I_{3 M}$ third molar maturity index
Table 3 Contingency table of the cutoff value's performance for boys $(n, 97)$

\begin{tabular}{llll}
\hline Test & Age & Total \\
\cline { 2 - 4 } & $<18$ & 218 & \\
\hline$I_{3 M}<0.08$ & 0 & 32 & 52 \\
$I_{3 M} \geq 0.08$ & 42 & 55 & 45 \\
Total & 42 & & 97 \\
\hline
\end{tabular}

$I_{3 M}$ third molar maturity index

medicine must be accurate, precise, and well-validated before application (Rivera et al. 2017).

The estimation of dental age in Egyptians was reported in previous studies (El-Bakary et al. 2010; Zaher et al. 2011; El Morsi et al. 2015; Wahdan et al. 2017). But, to the best of our knowledge, this is the first Egyptian study that validates the use of the third molar maturity index cutoff value of 0.08 to discriminate those aged 18 years or older from minors (less than 18 years).

In his original study, Cameriere et al. (2008) evaluated the $\mathrm{I}_{3 \mathrm{M}}$ in OPGs of 906 Caucasian Italian individuals aged between 14 and 23 years (53.6\% females and $46.4 \%$ males). The cutoff value of 0.08 showed $70 \%$ sensitivity and $98 \%$ specificity with $83 \%$ correct classification. This cutoff value was tested in many populations around the world and showed high sensitivity and specificity although percentages were different.

Results of this Egyptian sample showed relatively faster development (earlier complete maturation of the third molar) in boys. Generally, many studies showed male precedence of the third molar development, e.g., Hispanics (Solari and Abramovitch 2002), Japanese (Olze et al. 2004), Serbian (Zelic et al. 2016), and Saudi (AlQahtani et al. 2017). Nevertheless, females were reported to show faster development of third molars in one study (Liversidge 2008).

When the cutoff value of " $\mathrm{I}_{3 \mathrm{M}}=0.08$ " was evaluated in the present study (247 cases), the high sensitivity (Se) of the test in boys (95\%) but relatively lower sensitivity in girls (73\%) was documented. Sensitivity values were reported to be over 95\% in Turkish males (128 boys from 293 total sample) (Gulsahi et al. 2016), Colombians (288 children), (De Luca et al. 2016), and Serbians (598 cases) (Zelic et al. 2016). Meanwhile, it was $88 \%$ in Botswana (1294 individuals) (Cavrić et al. 2016) and 90\% in Australians (143 cases) (Franklin et al. 2016). Unfortunately, sensitivity was only $52 \%$ in the Saudi population (300 cases) (AlQahtani et al. 2017).

Meanwhile, a high specificity ( $\mathrm{Sp}$ ) of the cutoff value (100\% in boys and $97 \%$ in girls) was found in the present sample. On the other hand, specificity was $100 \%$ in the Turkish study (Gulsahi et al. 2016) and in Saudi males (AlQahtani et al. 2017), and over $85 \%$ in Colombians 
(De Luca et al. 2016), Serbians (Zelic et al. 2016), Botswana (Cavrić et al. 2016), and Australian population (Franklin et al. 2016).

It seems that values of sensitivity and specificity of the present study are more in boys ensuring previous published data in Serbians (Zelic et al. 2016). On the other hand, girls showed more values in a Colombian study (De Luca et al. 2016).

Different sensitivity and specificity in these populations may be either due to actual differences between them or differences in the age distribution and sample size, as well as dissimilarity among observers. However, the examination of the third molars may provide reasonable accuracy for the likelihood that a person is at least 18 years old (Acharya et al. 2014).

In the present Egyptian sample, the proportion of correctly classified persons was $97 \%$ in boys and $82 \%$ in girls, even better than $83 \%$ reported by Cameriere et al. (2008). More or less similar proportions of correctly classified individuals were reported in Turkish (97.6\% for boys and 92.7\% in girls) (Gulsahi et al. 2016), Serbians (95\% in males and 91\% in females) (Zelic et al. 2016), and Chileans (83\%) (Cameriere et al. 2018).

Meanwhile, the positive predictive value (PPV) in the present Egyptian sample was $60 \%$ in boys and $59 \%$ in girls. Although the PPV is highly useful, it is sensitive to the prevalence of the positive test group (older age category) and can rarely be generalized beyond the study sample (Gulsahi et al. 2016). In a legal and forensic context, it is ethically safer to underestimate age than to overestimate age due to constitutional and judicial implications when involving a possible adult (Cavrić et al. 2016).

Technically, unacceptable errors can be detected if an adult was wrongly diagnosed as a minor (less than 18 years). They will get the full benefit of safeguarding through being children in care. However, if the reverse occurs and a minor was diagnosed as over 18 years, this is an ethically unacceptable error as it leads to violation of minors' rights (Garamendi et al. 2005).

In the context of estimating a person's age, none of the techniques can be used with high reliability when the person has completed his growth. However, from the legal point of view, it is often enough to indicate whether a person is an adult or a minor (Schmeling et al. 2008).

\section{Conclusion}

In conclusion, the third molar maturity index can discriminate between individuals who are 18 years and over and those under 18 with higher accuracy in boys than girls. As the present findings are in correlation with findings for other populations, the $\mathrm{I}_{3 \mathrm{~m}}$ cutoff value is justifiable to be used in medicolegal practice.

\section{Abbreviations}

$\mathrm{I}_{3 \mathrm{M}}$ : Third molar maturity index; ICC: Intra-class correlation coefficient: OPGs: Orthopantographs; PPV: The positive predictive value; Se: Sensitivity; Sp: Specificity

\section{Acknowledgements}

None

Authors' contributions

AAE-B contributed to the idea of the research and the study design, collecting of the data, rating of panoramas, and writing and publishing the article. SME-A shared in the rating of panoramas and writing the research. HMAEA shared in the rating of panoramas. VPLA contributed to the statistical analysis and shared in writing the paper. RC contributed to the statistical analysis and revised the paper. All authors read and approved the final manuscript.

\section{Funding}

This research was not financially supported by any organization.

\section{Availability of data and materials}

Data supporting our findings can be found with the corresponding author. Data will not be shared, as it contains personal information. Please contact the author for data requests.

Ethics approval and consent to participate

This study was conducted in Mansoura University, Egypt, and approved by Mansoura University IRB (code: R.18.11.345).

Consent for publication

This study does not include publishing of personal data.

\section{Competing interests}

The authors declare that they have no competing interests.

\section{Author details}

${ }^{1}$ Forensic Medicine and Clinical Toxicology Department, Faculty of Medicine, Mansoura University, Mansoura 35516, Egypt. ²Radiology Department, Student's Hospital, Mansoura University, Mansoura, Egypt. ${ }^{3}$ AgEstimation Project, University of Macerata, Macerata, Italy.

Received: 1 May 2019 Accepted: 27 August 2019

Published online: 14 September 2019

\section{References}

Acharya AB, Bhowmik B, Naikmasur VG (2014) Accuracy of identifying juvenile/ adult status from third molar development using prediction probabilities derived from logistic regression analysis. J Forensic Sci 59(3):665-670

AlQahtani S, Kawtharb A, AlAraikb A, AlShalanb A (2017) Third molar cut-off value in assessing the legal age of 18 in Saudi population. Forensic Sci Int 272:64-67

Cameriere R, De Luca S, Cingolani M, Ferrante L (2015) Measurements of developing teeth and carpals and epiphyses of the ulna and radius for assessing new cut-offs at the age thresholds of 10,11, 12, 13 and 14 years. J Forensic Legal Med 34:50-54

Cameriere R, Ferrante L, De Angelis D, Scarpino F, Galli F (2008) The comparison between measurement of open apices of third molars and Demirjian stages to test chronological age of over 18 year olds in living subjects. Int J Legal Med 122:493-497

Cameriere R, Velandia Palacio LA, Pinares J, Bestetti F, Paba R, Coccia E, Ferrante L (2018) Assessment of second (I2M) and third (I3M) molar indices for establishing 14 and 16 legal ages and validation of the Cameriere's I3M cutoff for 18 years old in Chilean population. Forensic Sci Int 285:205.e1-205.e5

Cavrić J, Galić I, Vodanović M, Brkić H, Gregov J, Viva S, Rey L, Cameriere R (2016) Third molar maturity index (I3M) for assessing age of majority in a black African population in Botswana. Int J Legal Med 130:1109-1120

Declaration of Helsinki (2013) WMA Declaration of Helsinki-Ethical Principles for Medical Research Involving Human Subjects. https://www.wma.net/policiespost/wma-declaration-of-helsinki-ethical-principles-for-medical-researchinvolving-human-subjects/. 
De Luca S, Aguilar L, Rivera M, Velandia Palacio LA, Riccomi G, Bestetti F, Cameriere R (2016) Accuracy of cut-off value by measurement of third molar index: study of a Colombian sample. Forensic Sci Int 261:160.e1-160.e5

Deitos AR, Costa C, Michel-Crosato E, Galić I, Cameriere R, Biazevic MG (2015) Age estimation among Brazilians: younger or older than 18? J Forensic Legal Med 33:111-115

Egypt Demographics Profile (2018), https://www.indexmundi.com/egypt/ demographics_profile.html. Accessed 15 Sept 2018

El Morsi D, Rezk H, Aziza A, El-Sherbiny M (2015) Tooth coronal pulp index as a tool for age estimation in Egyptian population. J Forensic Sci Crimino 3:201-208

El-Bakary AA, Hammad SM, Mohammed F (2010) Dental age estimation in Egyptian children, comparison between two methods. J Forensic Legal Med 17(7):363-367

Franklin D, Flavel A, Noble J, Swift L, Karkhanis S (2015) Forensic age estimation in living individuals: methodological consideration in the context of medicolegal practice. Res Rep Forensic Med Sci 5:53-66

Franklin D, Karkhanis S, Flavel A, Collini F, De Luca S, Cameriere R (2016) Accuracy of a cut-off value based on the third molar index: validation in an Australian population. Forensic Sci Int 266:575.e1-575.e6

Galic I, Lauc T, Brkić H, Vodanovic M, Galic E, Biazevic MG, Brakus I, Badrov J, Cameriere R (2015) Cameriere's third molar maturity index in assessing age of majority. Forensic Sci Int 252:191-195

Garamendi PM, Landa MI, Ballesteros J, Solano MA (2005) Reliability of the methods applied to assess age minority in living subjects around 18 years old. A survey on a Moroccan origin population. Forensic Sci Int 154:3-12

Gulsahi A, De Luca S, Cehreli SB, Tirali RE, Cameriere R (2016) Accuracy of the third molar index for assessing the legal majority of 18 years in Turkish population. Forensic Sci Int 266:584.e1-584.e6

Gupta S, Mehendiratta M, Rehani S, Kumra M, Nagpal R, Gupta R (2015) Age estimation in Indian children and adolescents in the NCR region of Haryana: a comparative study. J Forensic Dent Sci 7(3):253-258

Liversidge HM (2008) Timing of human mandibular third molar formation. Ann Hum Biol 35:294-321

Olze A, Taniguchi M, Schmeling A, Zhu BL, Yamada Y, Maeda H et al (2004) Studies on the chronology of third molar mineralization in a Japanese population. Legal Med 6:73-79

Rivera M, De Luca S, Aguilar L, Velandia Palacio LA, Galil CR (2017) Measurement of open apices in tooth roots in Colombian children as a tool for human identification in asylum and criminal proceedings. J Forensic Legal Med 48:9-14

Schmeling A, Grundmann C, Fuhrmann A, Kaatsch HJ, Knell B, Ramsthaler F et al (2008) Criteria for age estimation in living individuals. Int I Legal Med 122:457-460

Solari AC, Abramovitch K (2002) The accuracy and precision of third molar development as an indicator of chronological age in Hispanics. J Forensic Sci 47:531-535

Wahdan AA, Lashin HI, Elborae MO (2017) Estimation of age using mandibular permanent first molars in panoramic radiographs in a sample of Egyptian population, Mansoura. J Forens Med Clin Toxicol 25(2):1-12

Zaher JF, Fawzy IA, Habib SR, Ali MM (2011) Age estimation from pulp/tooth area ratio in maxillary incisors among Egyptians using dental radiographic images. J Forensic Legal Med 18:62-65

Zelic K, Galic I, Nedeljkovic N, Jakovljevic A, Milosevic O, Djuric M, Cameriere R (2016) Accuracy of Cameriere's third molar maturity index in assessing legal adulthood on Serbian population. Forensic Sci Int 259:127-132

\section{Publisher's Note}

Springer Nature remains neutral with regard to jurisdictional claims in published maps and institutional affiliations.

\section{Submit your manuscript to a SpringerOpen ${ }^{\circ}$ journal and benefit from:}

- Convenient online submission

- Rigorous peer review

- Open access: articles freely available online

High visibility within the field

- Retaining the copyright to your article

Submit your next manuscript at $\boldsymbol{\nabla}$ springeropen.com 